\title{
Allergic Manifestation in Paediatric Patients with Primary Immunodeficiency Diseases
}

\author{
Joanna Pawłowska \\ Department of Pediatrics and Allergy, Medical University \\ of Lodz, Korczak Pediatric Centre, Lodz, Poland \\ (iD) https://orcid.org/0000-0003-1864-7542 \\ Corresponding author: asiap06@gmail.com

\section{Agnieszka Sobocińska} \\ Department of Pediatrics and Allergy, Medical University \\ of Lodz, Korczak Pediatric Centre, Lodz, Poland \\ (iD) https://orcid.org/0000-0001-9834-7923 \\ Izabela Kałuzińska-Parzyszek \\ Department of Pediatrics and Allergy, Medical University \\ of Lodz, Korczak Pediatric Centre, Lodz, Poland \\ (iD) https://orcid.org/0000-0002-7743-7521

\section{Joanna Jerzyńska} \\ Department of Pediatrics and Allergy, Medical University \\ of Lodz, Korczak Pediatric Centre, Lodz, Poland \\ (iD) https://orcid.org/0000-0002-8042-406X

\section{Agnieszka Brzozowska} \\ Department of Pediatrics and Allergy, Medical University \\ of Lodz, Korczak Pediatric Centre, Lodz, Poland \\ (iD) https://orcid.org/0000-0002-8988-189X
}

DOI: https://doi.org/10.20883/medical.e442

Keywords: immunodeficiencies, allergy, asthma, atopy, allergic manifestation

Published: 2020-10-29

How to cite: Pawłowska J, Sobocińska A, KałuzińskaParzyszek I, Jerzyńska J, Brzozowska A. Allergic Manifestation in Paediatric Patients with Primary Immunodeficiency Diseases. JMS [Internet]. 2020 Oct 29;89(4):e442. doi:10.20883/medical.e442

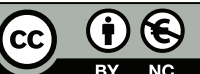

(C) 2020 by the author(s). This is an open access article distributed under the terms and conditions of the Creative Commons Attribution (CC BY-NC) licencse. Published by Poznan University of Medical Sciences

\begin{abstract}
Introduction. Primary immunodeficiency diseases (PID) are a diverse group of rare genetic disorders that affect the development and/or function of the immune system. Affected individuals are predisposed to an increased rate and severity of infections, allergy, autoimmunity and malignancy. Primary immunodeficiency diseases are considered rare; physicians and general practitioners have little knowledge about the clinical presentation, diagnostic approach and health impact of PID. Many PID patients have a clinical history in favour of allergic diseases. Nevertheless, in these patients, the importance and prevalence of atopic disorders have not been completely explained.

Aim. The aim of this study was to evaluate atopic presentations, including atopic dermatitis, allergic rhinitis and asthma in a group of PID patients under the care of our clinic.

Material and Methods. Fifty-seven pediatric patients with PID primary immunodeficiency diseases were enrolled from March 2018 to April 2019. Serum IgE levels were measured. Information regarding the patient's history of allergic diseases, including asthma, allergic rhinitis and atopic dermatitis were analysed.

Results and Conclusions. Confirmed allergy/asthma was found in 40 patients (70\%). Thirty-eight patients $(66.7 \%)$ had a diagnosis of asthma, 7 patients (12.3\%) of allergic rhinitis and $13(22.8 \%)$ of atopic dermatitis. Serum IgE total level was elevated in 12 patients $(21 \%)$.
\end{abstract}

\section{Introduction}

Immunodeficiency diseases (ID) involve a quantitative and/or functional disorder in the immune system [1] that can result in a greater susceptibility to infections, immunological disruption, autoimmunological dysregulation, inflammation and malignancy. If the origin is genetic, it is classified 
as primary immunodeficiency disorder (PID) and as secondary immunodeficiency disorder (SID) if acquired. To date, about 300 separate primary immunodeficiency disorders have been defined [2], in most cases they are antibody disorders (56.7\%), other well defined PIDs (13.9\%), phagocytic disorders (8.7\%), T-cell deficiencies (7.5\%) and complement deficiencies (4.9\%) [3]. An incidence of PID is estimated as $41-83 / 100.000$ population, according to most studies [4].

There are reports about a probable correlation between some PID and allergic diseases, due to their common atopic presentations. A lot of patients affected by PID manifest a clinical history which may suggest an allergic asthma, allergic rhinitis or atopic dermatitis [5-8].

There is some data indicating that immunodeficiencies, for example, hyper-IgE syndrome and Wiskott-Aldrich syndrome, may have an atopic component. In other PID, mainly those considering antibody deficiencies, atopy is more prevalent than in normal population, however its role has not been fully revealed [9]. Since patients with PID and allergic disease first present to a specialist with alike complaints, these two disease groups regularly take the same place in their differential diagnosis.

\section{Aim}

The aim of this study was to evaluate atopic presentations, including atopic dermatitis, allergic rhinitis and asthma in a group of PID patients.

\section{Material and Methods}

\section{Study Design and Subjects}

The study was conducted in the Department of Pediatrics and Allergy, Medical University of Lodz, Poland, from March 2018 to April 2019. Fifty-seven patients (38 males and 19 females) aged 4-18 years, with a diagnosis of primary immunodeficiencies who attended our department at that time, were enrolled in the study.

The diagnosis was established previously and the patients were evaluated due to the clinical and laboratory criteria of PID, according to the International Union of Immunological Societies (IUIS) Primary Immunodeficiency Diseases Classification Committee [6,9].
Data including age, history of asthma, allergic rhinitis and atopic dermatitis were collected from all patients by analysis of medical documentation and medical interviews. Total serum IgE levels and specific IgE level (against Dermatophagoides pteronyssinus, Dermatophagoides farinae, Cladosporium, Alternaria, cat and dog dander, Aspergillus, grass mix and tree mix) were measured (by using ImmunoCAP method) in all patients. Allergic rhinitis, atopic dermatitis and asthma diagnosis were defined according to international guidelines [10-12]. Diagnosis was confirmed by a specialist and documented.

\section{Results}

Fifty-seven eligible patients (66\% males and $33 \%$ females) were enrolled into the analysis. Within the study group, 20 patients (35\%) suffered from hypogammaglobulinaemia, 31 patients (54\%) had IgG subclass deficiency, 3 patients (5\%) had common variable immunodeficiency, and 3 (5\%) patients were diagnosed with agammaglobulinaemia (Figure 1).

Confirmed allergy/asthma was found in 40 patients $(70 \%)$. The allergic evaluation revealed that 38 patients $(66.7 \%)$ had a diagnosis of asthma, 13 patients $(22.8 \%)$ had a clinical history of atopic dermatitis and 7 patients (12.3\%) suffered from allergic rhinitis (Figure 2). Fifteen patients (26.3\%) manifested at least two diseases amongst asthma, atopic dermatitis and allergic rhinitis, while 14 patients from the study group $(24.6 \%)$ were diagnosed with three of diseases.

.The IgE total level was elevated in 12 patients (21\%) and specific IgE level was detected also in

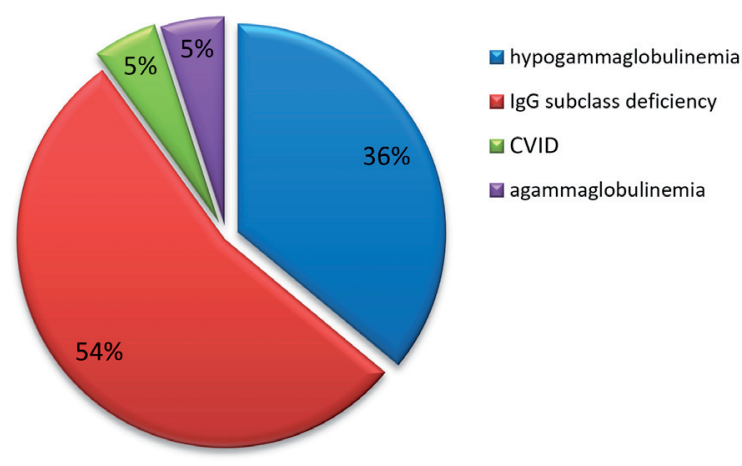

Figure 1. Characteristics of primary immunodeficiency in the study group 


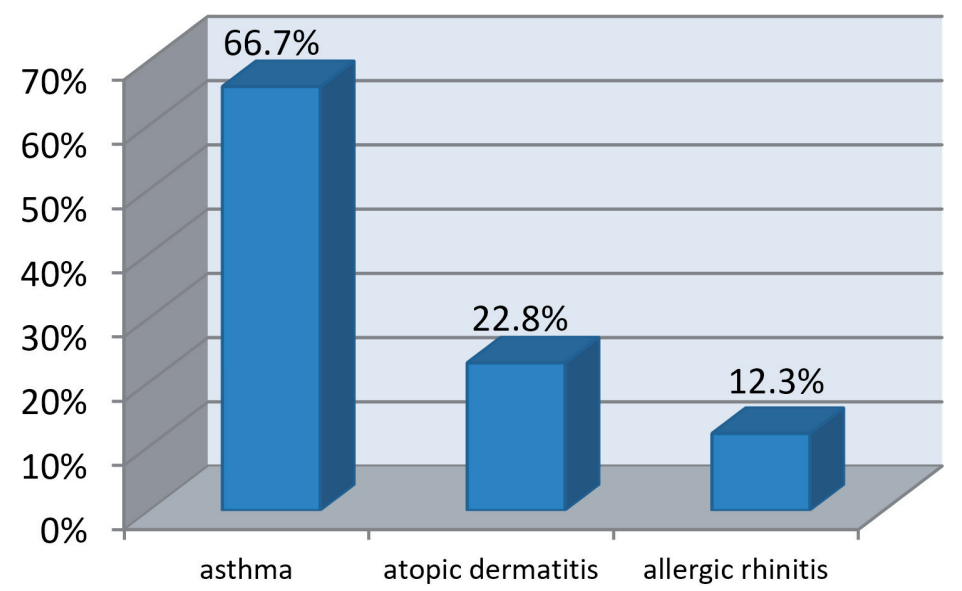

Figure 2. Patients with a positive history of allergic diseases in the study group

\section{IgE serum levels}

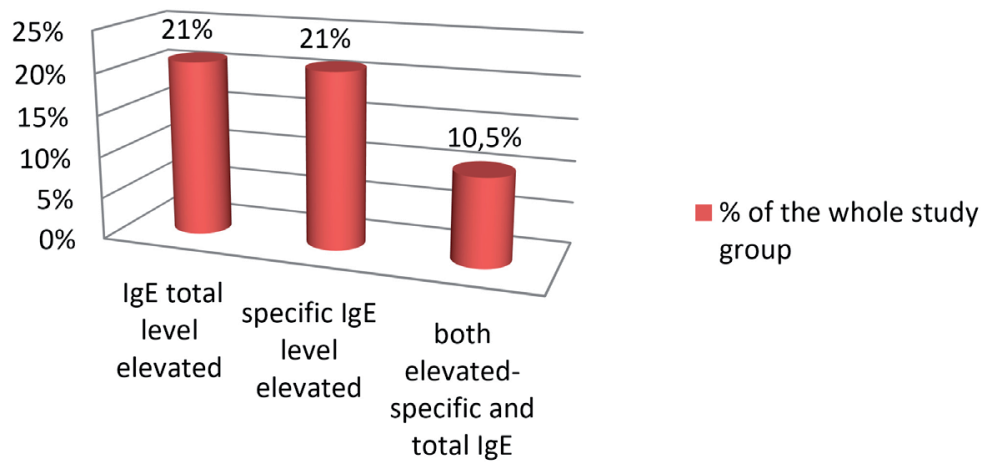

Figure 3. The percentage of patients with an elevated IgE in the study patients

12 patients $(21 \%)$, while the presence of specific IgE level accompanied by elevated IgE total level was observed in 6 patients (10.5\%) (Figure 3).

In this study, asthma was the most common (66.7\%) atopic manifestation in PID patients; allergic rhinitis and atopic dermatitis were $12.3 \%$ and $22.8 \%$ respectively.

\section{Discussion}

This study was carried out to extend our knowledge about atopies in children diagnosed with PID. Several studies have reported that the frequency of atopy and allergic disease may be higher in patients with PID [9] than the general population.

Allergic disorders and primary immunodeficiency may appear simultaneously. The large surface area of the respiratory, genitourinary, gas- trointestinal system enable the potential invasion of pathogens. It is known that secretory IgA (its production may be insufficient in PID patients) acts an important role in the protection of the body through particular immune receptors and modulators. Secretory $\lg A$ also acts as a relevant antibody supervising allergic symptoms and limiting allergens to lamina propria, thus reducing the inflammatory response [13]. Remittent infections may not only be with regard to immunodeficiency but also an allergic background has a significant role in clinical presentation $[14,15]$. In our population, $70 \%$ of patients with PID had allergic/ asthma diseases.

Further studies have shown evidence linking antibody deficiency with asthma, which may indicate a higher prevalence of asthma in patients with PID than the normal population [16]. Importantly the United States Immunodeficiency Network (USIDNET) imply that asthma, 
not bronchiectasis, is the most prevalent respiratory disorder among CVID patients [16]. There are also data insinuating that some asthma affected patients may also suffer from underlying PID which might not be diagnosed [17]. An impaired immune defence leading to remittent infections can cause a chronic inflammatory response, resulting in airway hyperreactivity, remodelling, and ultimately to fixed obstruction.

At the beginning of the infectious-inflammatory process, convertible changes might be clinically assessed as asthma [18]. There are opinions that remittent sinopulmonary infections with regard to PID, which might be underdiagnosed, could be the cause of chronic inflammation, resulting in hyperreactivity, damages and remodelling [16]. Identification of the role of PID as a participant in remittent infections and airway damage should refine the treatment of those potentially preventable forms of COPD.

There are reports of severe asthma in patients affected with high IgG subclass deficiency [9]. In our population, asthma was confirmed in $66.7 \%$ of patients. Furthermore, a positive role of antibiotic usage in early childhood in the development of asthma and allergic diseases is discussed. The risk of asthma development may be increased in children who undergo more than four antibiotic therapies during their first year of life [19]. From this perspective, many patients affected with PID could be at higher risk of developing asthma and allergy due to recurrent infections and frequent antibiotic courses during early childhood [15].

Allergic rhinitis is diagnosed on the basis of the patient's symptoms and specific IgE detection. Taking in consideration the abnormalities in the production of immunoglobulin and especially that the majority of CVID affected individuals do not produce $\lg \mathrm{E}[5]$, it is noticeable that the detection of specific IgE to aeroallergens, as a diagnostic standard for allergic rhinitis, might not be manageable. For that reason, CVID patients suspected of allergic rhinitis may require additional testing, for example, by nasal provocation with the most prevalent allergens [6]. In our population, AR was diagnosed in $12.3 \%$ cases. A feasible illumination for the low detection of serum specific IgE in individuals affected CVID and allergic rhinitis can be their defective efficiency in producing immunoglobulins on a larger scale with continually present local specific IgE production to aeroallergens. According to some studies, the specific IgE local production in patients affected asthma or rhinitis was evaluated by detecting the transcription and mRNA expression of IgE in the local mucosa [20].

Approximately $50 \%$ of patients with PID show cutaneous manifestations. Skin infections are triggered frequently by Staphylococcus aureus and eczemas are the two most common ones. Eczematous dermatitis is one of the noninfectious skin manifestations in PID patients but is also commonly reported in the general population [21]. Thus, it is significant to be aware that the single presence of particular skin lesions does not always indicate immunological disorders. On the other hand, there are also some reports indicating that dermal alterations predated and were the grounds for clinical immunological diagnosis [22]. That is why the identification of precise skin symptoms in association with another clinical condition which may suggest immunity impairment and should point towards suspicion of underlying PID and consequently facilitate early recognition [23].

The frequent occurrence of allergies and asthma noticed in PID individuals may be considered as a result of an unstable equilibrium of the cellular and humoral immune system. The inclusion of reported atopic presentations in our study group may result in an over-estimation of its prevalence, but on the other hand, the overlapping of allergic disorders and immunodeficiency can be the reason for delayed recognition. The fact that pediatric patients with atopic disorders can present higher frequency and severity courses of infectious diseases is probable due to persistent inflammation in the airways and skin. Thus, manifestations descending from an impaired immune system may be recognised as part of the atopic disorder and vice versa [24].

Evaluation of atopy in PID patients is a challenge. Respiratory symptoms might be both a presentation of infectious complications or an allergic reaction of the respiratory tract. Moreover, PID, particularly CIVD, are often diagnosed belatedly $[15,25]$. A considerable cause of this situation might be the insufficient knowledge of PID amongst paediatricians, besides those in specialised centres. Contrarily, the high prevalence of remittent minor infections in children with an unaffected immune system and the significance of clinical overlapping with atopic disorders make 
it extremely difficult to establish a proper diagnosis. Paediatric patients who manifest atopic or autoimmune diseases and remittent infections should have at least their immunoglobulin levels evaluated to ensure exact treatment as quickly as possible. On a final note, it will minimalise the risk related to severe infection and improve the quality of life patients with chronic infectious diseases [24]. In summary, Atopic manifestations, including asthma, allergic rhinitis and eczema should be evaluated in patients with PID.

\section{Acknowledgements}

Conflict of interest statement

The authors declare no conflict of interest.

\section{Funding sources}

There are no sources of funding to declare.

\section{References}

1. Soler-Palacín P, de Gracia J, González-Granado LI, Martín C, Rodríguez-Gallego C, Sánchez-Ramón S, Group LI. Primary immunodeficiency diseases in lung disease: warning signs, diagnosis and management. Respiratory Research. 2018 Nov 12;19(1). https://doi. org/10.1186/s12931-018-0923-8

2. Shields AM, Patel SY. The primary immunodeficiency disorders. Medicine. 2017 Oct;45(10):597-604. https://doi.org/10.1016/j.mpmed.2017.07.011

3. Mahlaoui N, Gathmann B, Kindle G, EhI S, ESID Registry Working Party Steering Committee, ESID Society. The European Society for Immunodefciencies (ESID) Registry: recent advancements in the epidemiology of Primary Immunodefciencies and how does that translate in clinical care. Int J Public Health. 2014 Dec;1(4):25-7.

4. Kobrynski L, Powell RW, Bowen S. Prevalence and Morbidity of Primary Immunodeficiency Diseases, United States 2001-2007. Journal of Clinical Immunology. 2014 Sep 26;34(8):954-961. https://doi. org/10.1007/s10875-014-0102-8

5. Agondi RC, Barros MT, Rizzo LV, Kalil J, GiavinaBianchi P. Allergic asthma in patients with common variable immunodeficiency. Allergy. 2010 04;65(4):510-515. https://doi.org/10.1111/j.1398-9995 .2009.02211.x

6. Agondi RC, Barros MT, Kokron CM, Cohon A, Oliveira AK, Kalil J, Giavina-Bianchi P. Can Patients with Common Variable Immunodeficiency Have Allergic Rhinitis?. American Journal of Rhinology \& Allergy. 2013 Mar;27(2):79-83. https://doi.org/10.2500/ ajra.2013.27.3855

7. Gernez $Y$, Freeman AF, Holland SM, Garabedian E, Patel NC, Puck JM, Sullivan KE, Akhter J, Secord $E$, Chen K, Buckley R, Haddad E, Ochs HD, Fuleihan R, Routes J, Muskat M, Lugar P, Mancini J, Cunningham-Rundles $\mathrm{C}$. Autosomal Dominant HyperIgE Syndrome in the USIDNET Registry. The Jour- nal of Allergy and Clinical Immunology: In Practice. 2018 May;6(3):996-1001. https://doi.org/10.1016/j. jaip.2017.06.041

8. Altun D, Akpınar $M$, Haskoloğlu ZŞ, Köste Bal $S$, Kavgacı A, Doğu EF, İkincioğulları KA. Immunoglobulin Isotype Deficiency Together with Allergic Diseases. Asthma Allergy Immunology. 2016 Dec 30;14(3):164-169. https://doi.org/10.21911/aai.6028

9. Özcan C, Metin A, Erkoçoğlu M, Kocabaş C. Allergic diseases in children with primary immunodeficiencies. Turk J Pediatr. 2014 Jan-Feb;56(1):41-7. PMID 24827946

10. The Global Initiative for Asthma (GINA), Main Report, 2019. https://ginasthma.org/wp-content/ uploads/2019/06/GINA-2019-main-report-June2019-wms.pdf

11. Eichenfield LF, Tom WL, Chamlin SL, Feldman SR, Hanifin JM, Simpson EL, Berger TG, Bergman JN, Cohen DE, Cooper KD, Cordoro KM, Davis DM, Krol A, Margolis DJ, Paller AS, Schwarzenberger K, Silverman RA, Williams $\mathrm{HC}$, Elmets $\mathrm{CA}$, Block J, Harrod CG, Smith Begolka W, Sidbury R. Guidelines of care for the management of atopic dermatitis. Journal of the American Academy of Dermatology. 2014 Feb;70(2):338-351. https://doi.org/10.1016/j. jaad.2013.10.010

12. Small $\mathrm{P}, \mathrm{Keith} \mathrm{PK}, \mathrm{Kim} \mathrm{H}$. Allergic rhinitis. Allergy, Asthma \& Clinical Immunology. 2018 Sep;14(S2). https://doi.org/10.1186/s13223-018-0280-7

13. Mantis N, Rol N, Corthésy B. Secretory IgA's complex roles in immunity and mucosal homeostasis in the gut. Mucosal Immunology. 2011 Oct 5;4(6):603-611. https://doi.org/10.1038/mi.2011.41

14. Szczawinska-Poplonyk A. An Overlapping Syndrome of Allergy and Immune Deficiency in Children. Journal of Allergy. 2012;2012:1-9. https://doi. org/10.1155/2012/658279

15. Dadkhah $M$, Aghamohammadi A, Movahedi $M$, Gharagozlou M. Atopic Manifestations: Dermatitis, Allergic Rhinitis and Asthma in Patients With Hypogammaglobulinemia. Iranian Journal of Pediatrics. 2015 Oct 6;25(5). https://doi.org/10.5812/ijp.2786

16. Berger M, Geng B, Cameron DW, Murphy LM, Schulman ES. Primary immune deficiency diseases as unrecognized causes of chronic respiratory disease. Respiratory Medicine. 2017 Nov;132:181-188. https:// doi.org/10.1016/j.rmed.2017.10.016

17. Baleeiro C, Mull N. Prevalence Of Common Variable Immunodeficiency (CVID) Among Patients With Recurrent Respiratory Tract Infections. B49. BRONCHIECTASIS: CYSTIC FIBROSIS AND BEYOND. American Thoracic Society 2010 International Conference, May 14-19, 2010 • New Orleans. 2010 May. https:// doi.org/10.1164/ajrccm-conference.2010.181.1_ meetingabstracts.a3187

18. Postma DS, Rabe KF. The Asthma-COPD Overlap Syndrome. Drazen JM. New England Journal of Medicine. 2015 Sep 24;373(13):1241-1249. https://doi. org/10.1056/nejmra1411863

19. Penders J, Kummeling I, Thijs C. Infant antibiotic use and wheeze and asthma risk: a systematic review and meta-analysis. European Respirato- 
ry Journal. 2011 Jan 13;38(2):295-302. https://doi. org/10.1183/09031936.00105010

20. Ying S, Humbert M, Meng Q, Pfister R, Menz G, Gould HJ, Kay A, Durham SR. Local expression of $\epsilon$ germline gene transcripts and RNA for the $\epsilon$ heavy chain of $\mathrm{IgE}$ in the bronchial mucosa in atopic and nonatopic asthma. Journal of Allergy and Clinical Immunology. 2001 Apr;107(4):686-692. https://doi.org/10.1067/ mai.2001.114339

21. Pichard DC, Freeman AF, Cowen EW. Primary immunodeficiency update. Journal of the American Academy of Dermatology. 2015 Sep;73(3):355-364. https:// doi.org/10.1016/j.jaad.2015.01.054

22. Moin A, Farhoudi A, Moin M, Pourpak Z, Bazargan N. Cutaneous manifestations of primary immunodeficiency diseases in children. Iran J Allergy Asthma Immunol. 2006 Sep;5(3):121-6. PMID 17237563
23. de Wit J, Brada RJK, van Veldhuizen J, Dalm VASH, Pasmans SGMA. Skin disorders are prominent features in primary immunodeficiency diseases: A systematic overview of current data. Allergy. $2018 \mathrm{Dec}$ 27;74(3):464-482. https://doi.org/10.1111/all.13681

24. Urschel S, Kayikci L, Wintergerst U, Notheis G, Jansson A, Belohradsky BH. Common Variable Immunodeficiency Disorders in Children: Delayed Diagnosis Despite Typical Clinical Presentation. The Journal of Pediatrics. 2009 Jun;154(6):888-894. https://doi. org/10.1016/j.jpeds.2008.12.020

25. Mohammadinejad $P$, Aghamohammadi A, Abolhassani $H$, Sadaghiani M, Abdollahzade S, Sadeghi B, Soheili H, Tavassoli M, Fathi S, Tavakol M, Behniafard N, Darabi B, Pourhamdi S, Rezaei N. Pediatric patients with common variable immunodeficiency: long-term follow-up. J Investig Allergol Clin Immunol. 2012;22(3):208-14. PMID 22697011 